\title{
Aplicação do percentual de abatimento de erosão em programas de conservação de solo e água na bacia do Itajaí
}

\author{
Maria Amélia Pellizzetti ${ }^{1}$ \\ Alexander Christian Vibrans ${ }^{2}$ \\ Beate Frank ${ }^{2}$ \\ ${ }^{1}$ Instituto Federal Catarinense - Campus Camboriú \\ Rua Joaquim Garcia, s/n - Caixa Postal 16 - 88340-000 - Camboriú - SC, Brasil. \\ mapellizzetti@yahoo.com.br \\ ${ }^{2}$ Universidade Regional de Blumenau \\ Rua São Paulo, 3250 - 89030-000 - Itoupava Seca - Blumenau - SC, Brasil. \\ acv@furb.br; frank.beate@gmail.com
}

\begin{abstract}
The establishment of percentages of erosion reduction is common within rural planification activities. The use of these values in programs of water and soil conservation stimulated by financial compensations comes to be a form to benefit land owners who adopt soil conservation practices. In this context, the National Water Agency (ANA), proposes financial compensation for landowners who convert to soil conservation measures. Therefore, it is necessary to know and to understand the reality of the rural actors, their socioeconomic background as well as the land productivity. The present work presents an evaluation of the potential impacts of the implantation of the "Water Producer Program" (PPA) in the Itajaí river basin, based on the analysis of eight small rural properties situated within the Itajaí river basin (SC) including the characterization of the actual land use and its possible alterations, and the attractiveness of this compensatory program. The results show that the PPA can serve as a tool to support the management of water resources in the Itajaí river basin.
\end{abstract}

Palavras-chave: uso do solo, práticas conservacionistas, políticas públicas para conservação de água e de solo, manejo de bacias hidrográficas.

\section{Introdução}

Na última década, a preocupação com a mudança das práticas de uso do solo na agricultura aumentou consideravelmente, devido a problemas de erosão, contaminação dos recursos hídricos e do solo, pela diminuição da fertilidade do solo e pela diminuição da produção em determinadas áreas agrícolas. $\mathrm{O}$ que parece ser intrínseco ao pensamento dos agricultores é a necessidade do uso constante do solo para a manutenção das atividades agrícolas, numa perspectiva convencional de seu uso.

Além disso, muitos agricultores têm receio em alterar as práticas tão comumente utilizadas na agricultura, uma vez que são produtos de uma evolução histórica, social e cultural no ambiente rural. Shaxson apud Monegat (1991) cita uma série de razões pela qual o agricultor pode não adotar práticas conservacionistas. Uma das razões é o fato dele não perceber a ocorrência da erosão em sua propriedade ou não considerá-la grave; o agricultor também pode não saber o que fazer para controlar a erosão ou sentir-se incapaz de fazê-lo; ou pode ainda não aceitar as recomendações por outras razões. Segundo esse autor, as maiores incertezas que os agricultores enfrentam são relativas: a) às políticas governamentais; b) aos custos e à disponibilidade de insumos; c) aos preços de mercado para os produtos agrícolas; d) aos riscos associados à aquisição de novas tecnologias; e e) às condições climáticas.

Devido a essas questões, as práticas de uso do solo continuam sendo extremamente agressivas ao meio ambiente, com a perda cada vez maior da fertilidade do solo e com o aumento de problemas causados, pela erosão, aos recursos hídricos. 
Em diversos casos, os agricultores não percebem diretamente a ligação entre os fatores econômicos e ambientais da produção agrícola, como justamente a queda na produção e nos rendimentos de suas culturas em decorrência do mau uso do solo. Diversos estudos sobre perdas de solo e de nutrientes comprovaram os impactos causados pela utilização de práticas convencionais e pela ausência de técnicas de cultivos conservacionistas nas propriedades rurais. Cogo et al. (2003) pesquisaram as perdas de solo e água por erosão hídrica, concluindo que perdas mais significativas ocorreram no preparo convencional sem cultivo e estabelecido no sentido do declive. Bertol et al. (2004) estudaram as perdas de fósforo e potássio por erosão hídrica, relacionadas ao método de preparo de solo.

Os agricultores, quando em situação econômica desfavorável, são levados a adiar as necessárias práticas de conservação do solo, procurando tirar da terra o máximo de rendimento imediato, a fim de vencerem suas dificuldades econômicas (Bertoni \& Lombardi Neto, 1999). Para que se consiga uma efetiva melhoria ambiental, é necessário que ocorra uma melhoria da condição sócio-econômica dos produtores rurais juntamente com a mudança das práticas adotadas. Essa mudança efetiva de atitude nas práticas agrícolas visa a diminuir o impacto ambiental gerado, reduzindo a perda de solo, procurando garantir a qualidade e a quantidade dos recursos hídricos na bacia hidrográfica e a manutenção das atividades agrícolas nas propriedades rurais.

O governo federal e alguns governos estaduais iniciaram programas para estimular a adoção de práticas conservacionistas no meio rural. Programas de cunho compensatório por práticas conservacionistas, como o "Programa Produtor de Água" (ANA, 2003), prevêem, além da conservação do solo para a manutenção das atividades agrícolas nas propriedades rurais, a conservação dos recursos hídricos, servindo como ferramenta de apoio à gestão de recursos hídricos.

O presente trabalho tem o objetivo de analisar oito pequenas propriedades rurais, consideradas representativas da Bacia Hidrográfica do Rio Itajaí (SC), para avaliar a possibilidade de implantação do "Programa Produtor de Água" na região. A análise tratou da identificação do uso atual do solo e das culturas predominantes; levantando as áreas florestais, as Áreas de Preservação Permanente e de Reserva Legal, bem como as áreas reflorestadas com espécies exóticas; das possíveis alterações do padrão de uso do solo nas propriedades, identificando as práticas conservacionistas adequadas e praticáveis na região de estudo. Por fim, foi avaliada a disposição dos agricultores de alterar o padrão de uso do solo atual através de incentivos financeiros.

\section{Material e Métodos}

Inicialmente foram realizadas entrevistas com os técnicos extensionistas da Empresa de Pesquisa Agropecuária e Extensão Rural de Santa Catarina S.A. (EPAGRI) em seus escritórios municipais, com a finalidade de obter informações sobre a realidade ambiental e social das comunidades locais e identificação de propriedades representativas. Em seguida foram realizadas visitas às propriedades rurais selecionadas, envolvidas com as culturas de fumo, cebola, hortaliças e frutas, alimentos agroecológicos, gado de leite e gado de corte (Figura 1). 


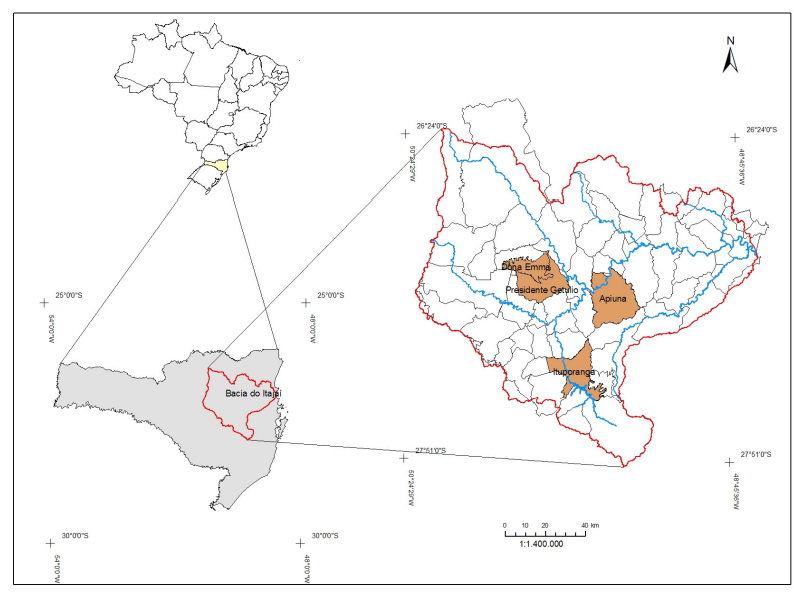

Figura 1. Localização da bacia hidrográfica do rio Itajaí (SC), com destaque aos municípios pesquisados.

As propriedades pesquisadas nos municípios selecionados foram caracterizadas como pequenas propriedades rurais, possuindo entre 18 e $32 \mathrm{ha}$. Segundo os dados disponibilizados em ICEPA (2005), verifica-se que na bacia do Itajaí predominam as pequenas propriedades rurais, com atividades agropecuárias, com área entre 10 e 20 ha. $\mathrm{O}$ grupo das propriedades com até 50 ha de extensão compreende $91,94 \%$ das propriedades. Foram selecionadas duas pequenas propriedades rurais em cada um dos quatro municípios - Apiúna, Dona Emma, Presidente Getúlio e Ituporanga, conforme demonstrado na Tabela 1.

Tabela 1. Relação das propriedades pesquisadas, suas culturas e localização nos municípios selecionados

\begin{tabular}{|c|c|c|c|c|}
\hline Município & $\begin{array}{c}\text { Região } \\
\text { do } \\
\text { Vale }\end{array}$ & Cultura Principal & $\begin{array}{l}\text { Código da } \\
\text { Propriedade }\end{array}$ & $\begin{array}{c}\text { Área } \\
\text { (ha) }\end{array}$ \\
\hline \multirow{2}{*}{ Apiúna } & \multirow{2}{*}{ Médio } & Olericultura & 1 & 24,2 \\
\hline & & Gado de corte e fumo & 2 & 31,0 \\
\hline \multirow{2}{*}{$\begin{array}{l}\text { Dona } \\
\text { Emma }\end{array}$} & \multirow{2}{*}{ Alto } & Fumo & 3 & 26,0 \\
\hline & & Gado de leite e fumo & 4 & 18,0 \\
\hline \multirow[t]{2}{*}{ Ituporanga } & \multirow[t]{2}{*}{ Alto } & $\begin{array}{c}\text { Cebolicultura e Gado } \\
\text { de leite }\end{array}$ & 5 & 18,0 \\
\hline & & Cebolicultura & 6 & 28,3 \\
\hline \multirow{2}{*}{$\begin{array}{l}\text { Presidente } \\
\text { Getúlio }\end{array}$} & \multirow{2}{*}{ Alto } & $\begin{array}{l}\text { Gado de leite e } \\
\text { olericultura }\end{array}$ & 7 & 32,0 \\
\hline & & $\begin{array}{c}\text { Alimentos } \\
\text { agroecológicos }\end{array}$ & 8 & 24,5 \\
\hline
\end{tabular}

Para a obtenção dos dados físicos das propriedades foram realizadas visitas a campo. A área total e as áreas cultivadas em cada propriedade foram demarcadas com o auxílio de GPS de navegação (Etrex Vista, Garmin) e de clinômetro. Com base nos dados levantados com GPS foram elaborados croquis das propriedades, processados no software Auto CAD.

A partir do levantamento das práticas agrícolas encontradas em cada propriedade realizouse a comparação das práticas existentes $\left(Z_{0}\right)$, com a simulação das práticas conservacionistas $\left(\mathrm{Z}_{1}\right)$ considerando as técnicas desejáveis ou possíveis, utilizando-se os valores adaptados de Pundek (1994;1998). A simulação das práticas agrícolas foi pensada partindo de um cenário 
convencional para um cenário conservacionista aplicável em todas as propriedades analisadas. Esse procedimento foi adotado porque, mesmo que já ocorram práticas conservacionistas nas propriedades, observou-se certa inconstância do uso do solo pelos agricultores, que a cada safra modificam suas técnicas de cultivo, não estabelecendo assim uma melhoria ambiental consistente e contínua. Também foram estimadas, através dos dados coletados em campo, as áreas de preservação permanente que deveriam existir nas propriedades rurais pesquisadas, caso a legislação ambiental vigente fosse aplicada.

Os valores previstos para as compensações financeiras foram calculados para as propriedades pesquisadas, com base nos valores propostos pelo "Programa Produtor de Água”. A partir destes resultados realizou-se nova visita às propriedades, com o intuito de verificar a atratividade do Programa para os proprietários.

\section{Resultados e Discussão}

Os resultados da pesquisa das propriedades rurais pesquisadas são apresentados, de forma resumida, na Tabela 2.

Tabela 2. Quantificação das áreas das propriedades pesquisadas por tipo de uso (APP - área de preservação permanente, RL - reserva legal, PPA - produtor de água)

\begin{tabular}{cccccccc}
\hline Código & $\begin{array}{c}\text { Área } \\
\text { (ha) }\end{array}$ & $\begin{array}{c}\text { APP } \\
\text { estimada }\end{array}$ & RL & $\begin{array}{c}\text { APP } \\
\text { em } \\
\text { RL }\end{array}$ & $\begin{array}{c}\text { Mata } \\
\text { Nativa }\end{array}$ & $\begin{array}{c}\text { Compensação } \\
\text { máxima PPA }\end{array}$ & $\begin{array}{c}\text { Compensação } \\
\text { máxima com } \\
\text { Mata Nativa }\end{array}$ \\
\hline 1 & 24,2 & 4,50 & 4,85 & 6,05 & 12,48 & 644,54 & $1.892,93$ \\
2 & 31,0 & 2,95 & 6,20 & 7,75 & 4,35 & $2.033,39$ & $2.467,70$ \\
3 & 26,0 & 2,80 & 5,20 & 6,50 & 0,87 & $1.683,75$ & $1.770,75$ \\
4 & 18,0 & 6,15 & 3,60 & 4,50 & 0,00 & $1.472,50$ & 0,00 \\
5 & 18,0 & 3,45 & 3,60 & 4,50 & 4,60 & $1.113,25$ & $1.574,25$ \\
6 & 28,3 & 2,35 & 5,65 & 7,10 & 8,80 & $1.607,50$ & $2.484,50$ \\
7 & 32,0 & 1,90 & 6,40 & 8,00 & 13,45 & $1.204,00$ & $2.547,00$ \\
8 & 24,5 & 5,65 & 5,00 & 6,15 & 10,00 & $1.042,72$ & $2.044,63^{1}$ \\
\hline
\end{tabular}

A coluna "APP estimada" mostra a extensão das áreas de preservação permanente que deveriam existir nas propriedades rurais, considerando áreas ao redor de nascentes e ao longo de cursos d'água, de acordo com a legislação vigente.

Entende-se como "RL" a Reserva Legal obrigatória, compreendendo $20 \%$ da propriedade. Nenhuma das propriedades pesquisadas possui a sua reserva legal averbada em cartório. Para a averbação das áreas de preservação permanente, seriam necessários $25 \%$ do total da propriedade, igualmente calculados e apresentados na tabela acima, na coluna "APP em RL".

O valor recomendado pelo "Programa Produtor de Água" (ANA, 2003) é mostrado na Tabela 2 na coluna compensação máxima PPA, considerando somente as conversões de práticas agrícolas utilizadas na região de estudo, segundo dados de Pundek (1994;1998). Considerando a presença e a manutenção de matas nativas na propriedade como critério para

\footnotetext{
1 Para a propriedade PG02 foram calculados valores para a compensação financeira pela atividade de meliponicultura, podendo atingir o valor total de $\mathrm{R} \$ 4.459,53 /$ ano caso o produtor rural disponibilizasse as colméias para uso em áreas diversificadas da bacia do Itajaí. Os valores finais calculados para a atividade de meliponicultura foram baseados nos valores propostos no artigo "Polinização: atividade gera renda extra aos apicultores" (Revista SEBRAE AGRONEGÓCIOS, 2006).
} 
obtenção do beneficio monetário, o valor adotado pelo PPA seria ainda maior para sete das oito propriedades pesquisadas.

Embora tenha ficado claro nas visitas realizadas a campo, que muitas das técnicas utilizadas nas propriedades podem ser consideradas conservacionistas, não existe constância na execução destas práticas. Por esta razão, as compensações financeiras foram calculadas para a conversão das práticas convencionais de uso do solo para as práticas conservacionistas, como se ainda não tivessem sido aplicadas nas áreas pesquisadas.

De acordo com as informações levantadas em campo, observou-se que, para o cultivo de hortaliças e frutas, o percentual de abatimento de erosão viável para a região da bacia do Itajaí seria de 50\%, considerando o plantio em nível como uma prática de conservação do solo. Para as áreas de pastagens um percentual de abatimento de erosão de $52 \%$ poderia ser obtido, ao converter uma pastagem convencional para o sistema voisin de proteção de pastagens.

Com a utilização do plantio direto, o percentual de abatimento de erosão chegaria a 93\% para as culturas anuais presentes na bacia do Itajaí. Caso o sistema de tombo fosse considerado, conforme o recomendado por técnicos extensionistas para a propriedade 2, o percentual de abatimento de erosão seria de $85 \%$. A aração ainda é freqüentemente utilizada como técnica de preparo do solo na região estudada.

Para as áreas de reflorestamento com espécies nativas ou exóticas, o percentual de abatimento de erosão estimado seria de $99 \%$, uma vez que a biomassa das florestas plantadas proporciona a conservação do solo em longo prazo.

A identificação e efetiva proteção das áreas de preservação permanente previstas na legislação, a averbação e proteção da reserva legal nas propriedades e o manejo adequado das áreas cultivadas, baseados num planejamento das atividades agrícolas, podem melhorar, de forma significativa, o desempenho ambiental das propriedades no que se refere à redução de erosão e melhoria da qualidade da água dos mananciais..

De acordo com os proprietários pesquisados, a idéia de compensações financeiras por benefícios ambientais gerados através da utilização de práticas agrícolas conservacionistas é atrativa. Apenas os valores calculados para a propriedade 4 não foram atrativos para o proprietário, pois as práticas possíveis em suas glebas apresentam baixo percentual de abatimento de erosão, devido à textura do solo encontrado na propriedade.

Segundo a proposta apresentada pela Agência Nacional de Águas (2003), a período para a implantação do "Programa Produtor de Água" (denominado "período de maturação" do programa) seria de até cinco anos. Em geral, os agricultores pesquisados manifestaram opiniões favoráveis ao aumento na duração do incentivo financeiro do referido programa. Diante da difícil situação econômica da maioria dos agricultores, prazos diferenciados para a compensação financeira das práticas conservacionistas e também da manutenção das florestas nativas existentes nas propriedades poderiam ser estabelecidos. A compensação financeira pela presença de florestas nativas seria um estímulo permanente à efetiva conservação destas áreas, evitando a sua conversão para áreas de cultivo e mantendo as áreas de preservação permanente, a exemplo de topos de morro e de matas ciliares. A necessidade da manutenção das matas ciliares é imprescindível para a retenção de partículas do solo e das moléculas dos agrotóxicos carreadas com as mesmas.

Na bacia do Itajaí, 91,94\% das propriedades rurais se enquadram na classe com até 50 ha de extensão de terra (ICEPA, 2005). Segundo Vibrans (2003), a bacia possui uma área de 133.970 ha em lavouras e 200.960 ha em pastagens. Assumindo que, nas pequenas propriedades rurais, as áreas cultivadas ocupem $80 \%$ da sua área total, sendo o restante coberto por matas nativas ou por reflorestamentos, chega-se a aproximadamente 83.372 ha de áreas cultivadas. Neste caso, a adesão de todos os produtores rurais da bacia ao "Programa Produtor de Água" demandaria um valor aproximado de R $\$ 36.842 .200,00$ por ano, supondo 
incentivos financeiros máximos para mudanças nas culturas anuais (de $\mathrm{R} \$ 100,00$ por hectare - P.A.E $\leq 93 \%$ ), para as pastagens (de R $\$ 75,00$ por hectare - P.A.E $\leq 52 \%$ ) e para a manutenção de matas nativas e/ou reflorestamentos (de R\$100,00 por hectare - P.A.E $\leq$ 99\%). Este seria o valor máximo caso todos os agricultores da bacia do Itajaí aderissem ao programa simultaneamente e modificassem suas práticas agrícolas, ao ponto de merecer o valor máximo dos benefícios financeiros previstos. Os valores utilizados para esses cálculos foram obtidos com base nos referencias teóricos de Pundek (1994; 1998), observando diversos fatores do solo e das culturas tidas como representativas para a região, sendo apresentada a metodologia utilizado em artigo específico sobre a estimativa do percentual de abatimento de erosão para as condições da bacia do Itajaí.

\section{CONCLUSÕES}

1. De maneira geral, o "Programa Produtor de Água" seria aceito pelos produtores rurais pesquisados e pelos técnicos extensionistas da EPAGRI que acompanharam as ações da pesquisa. A idéia de compensar o produtor rural por atividades agrícolas conservacionistas foi considerada essencial para que a sua permanência no campo seja viável e para que a conservação ambiental dos recursos solo e água sejam efetivamente alcançadas.

2. Os valores calculados para cada propriedade mostraram-se atrativos para os proprietários pesquisados, sendo igualmente aceitos pelos técnicos extensionistas.

3. Na grande maioria dos casos, para as principais culturas agrícolas encontradas na bacia do Itajaí (fumo, cebola, mandioca, milho, olericultura e pecuária de corte e leiteira), as práticas de cultivo são caracterizadas como convencionais. Quando práticas conservacionistas são utilizadas, não ocorrem de forma constante e sistemática, mas, sim, dependendo da disponibilidade de tempo e de mão-de-obra de cada produtor.

4. Para a implantação do "Programa Produtor de Água" na bacia do Itajaí sugere-se o estabelecimento de propriedades modelo, onde o monitoramento das razões de perda de solo e volumes de água escoado e infiltrado seja realizado, de maneira a confirmar os valores obtidos através deste trabalho. Desta maneira, poderia-se evitar ou minimizar equívocos relacionados aos cálculos dos percentuais de abatimento de erosão através da utilização de práticas convencionais e conservacionistas de uso do solo.

\section{AGRADECIMENTOS}

Os autores agradecem ao Conselho Nacional de Desenvolvimento Científico e Tecnológico (CNPq) pela concessão da bolsa de mestrado, aos extensionistas da EPAGRI e aos produtores rurais pesquisados pelas informações cedidas.

\section{LITERATURA CITADA}

ANA - Agência Nacional de Águas. Manual operativo do programa “Produtor de Água”. Brasília: ANA, 65p, 2003.

Bertol, I.; Guadagnin, J. C.; Cassol, P. C.; Amaral, A. J.; Barbosa, F. T. Perdas de fósforo e potássio por erosão hídrica em um inceptisol sob chuva natural. Revista brasileira de ciência do solo, Campinas, v.28: p.485494, 2004. 
Bertoni, J.; Lombardi Neto, F. Conservação do solo. 4. ed. São Paulo: Ícone, $4^{a}$ edição. 355p, 1999.

Cogo, N.P.; R. Levien; R. A. Schwarz. Perdas de solo e água por erosão hídrica influenciadas por métodos de preparo, classes de declive e níveis de fertilidade do solo. Revista brasileira de ciência do solo, Campinas, v.27, p.743-753, 2003.

ICEPA. Levantamento agropecuário de Santa Catarina. Florianópolis: ICEPA, 255p, 2005.

Monegat, C. Plantas de cobertura del suelo: Características y manejo en pequeñas propiedades. Chapecó: Autor, 337p, 1991.

Pundek, M. Utilização prática da equação universal de perdas de solo para as condições de Santa Catarina. In: Manual de uso, manejo e conservação do solo e da água: Projeto de recuperação, conservação e manejo dos recursos naturais em microbacias hidrográficas. 2. ed. Florianópolis: EPAGRI, 384p, 1994.

Pundek, M. Utilização prática da equação universal de perdas de solo para as condições de Santa Catarina. Trabalho revisto não publicado. 1998. [Mensagem pessoal]. Mensagem recebida por <mapellizzetti@yahoo.com.br>.13 Out. 2006.

Vibrans, A.C. A cobertura florestal da Bacia do Rio Itajaí - elementos para uma análise histórica. Florianópolis: UFSC. 218p. Tese Doutorado. 2003. 